\title{
The use of corpora as translation resources. A study based on a survey of Spanish professional translators
}

\author{
Daniel Gallego-Hernández \\ Departamento de Traducción e Interpretación \\ University of Alicante
}

The aim of this paper is to describe the use that professional translators make of corpora as translation resources. First, we briefly review the literature on translation practitioners' use of corpora in the contexts of both translation training and professional translation. Then we present our survey-based study, analyse the uptake of corpora among Spanish translators and describe their use of this kind of translation resource. The results show that even if corpora are not as frequently used as other kinds of resources, such as dictionaries, there are professional translators who do use corpora, in a variety of ways, in their work. Additionally, non-users do not seem entirely sceptical about corpora. Against that backdrop, translator trainers are invited to continue to report on how corpora can be used as translation resources.

KEYWORDS: corpora as translation resources; professional translation; survey-based study

\section{The use of corpora as resources for translation practitioners}

Parallel texts, i.e. "texts that are related to the source text which provide information on text-type conventions or particularities of field-specific language use: terminological, collocational, phraseological, syntactical, etc.” (Sánchez-Gijón, 2009, p. 113), have long been, especially since the proliferation of information on the internet, an essential resource that complements other information resources, such as dictionaries or terminological databases, for translation practitioners facing specialised texts.

The potential that the internet brings to the practice of specialised translation has made it possible to associate work involving such texts with the exploitation of corpora, which are generally understood as collections of texts "held in machine-readable form and capable of being analysed automatically or semi-automatically in a variety of ways" (Baker, 1995, p. 225). Corpora may thus be conceived as sets of texts whose content may help translators to solve different kinds of problems according to their information needs. This is what Bowker (1998) first demonstrated when comparing translations carried out using conventional resources with others produced with the aid of specialised monolingual native-language corpora and corpus linguistics tools. Thus, the exploitation of corpora in the context of the practice of specialised translation does not involve reading a single text in detail, but reading different words, chunks or segments that occur frequently in the various texts in a corpus. Corpus linguistics tools (e.g. word frequency lists, n-gram frequency lists, concordances, and collocation profiles) can then be used to solve problems related to a variety of topics, such as terminology, phraseology, general language, source-text comprehension, and genre and discourse features.

Sánchez-Gijón (2002, p. 86-88) distinguishes between two basic types of corpora as translation aids: (1) stable corpora, which are large corpora available on the internet, and (2) ad hoc corpora, which are built by the translator. As Zanettin (2002) suggests, it is possible to add a third type, translation memories, which are "a very specialized kind 
of parallel corpus, and are usually relevant, reliable and well integrated into the translation work-flow. But of course translators do not have a translation memory ready for all occasions" (p. 247).

Stable corpora are often made available only after incorporation into their own interfaces, and are usually created to a specific design. Examples of such corpora are Brigham Young University's Corpus of Contemporary American English (COCA), with 450 million words (oral and written general texts), and the same institution's Corpus del Español, with 100 million words (oral and written texts). However, corpora of this type may not always be useful in specialised translation because they are often general and not adapted to translators' needs, as Zanettin (2002) points out, adding that "even the 100 million words BNC is ill-equipped to meet the needs of translators working with very specialized texts and confronted with specific terminology" (p. 240-241). Bowker \& Pearson (2002, p. 46-47) also argue that this kind of corpus has limitations as a translation resource when translating specialised texts. Furthermore, there appears to be a lack of such stable corpora in specialised areas, specific textual genres and different language combinations. For example, Gallego-Hernández (2013) notes that there seems to be no stable corpus available for use in the field of translator training courses for business translation from French into Spanish and vice versa, and translator trainers are compelled to implement ad hoc 'web for/as corpus' methodologies in their classes. Gallego-Hernández is currently working to create a specialised stable corpus called COMENEGO (Corpus Multilingüe de Economía y Negocios) (Gallego-Hernández \& Krishnamurthy, 2013).

Thus, when faced with a text belonging to a speciality for which there are no corpora available online, translators build their own corpora from the internet. These corpora may be referred to by different names, such as ad hoc corpora (Aston, 1999), disposable corpora (Varantola, 2000) or DIY corpora (Zanettin, 2002). They have also been defined in different ways:

Ad hoc corpora are compiled 'on the fly' by the translator in order to investigate a specific problem encountered during a particular translation. (Aston, 1999)

A DIY web corpus can be characterised as follows. It is a collection of internet documents, or more precisely of web pages in HTML. It is created ad hoc as a response to a specific text to be translated. It is an open corpus; more material can be added as the need arises. It is disposable (Varantola, 2000) or virtual (Ahmad, Holmes-Higgin \& Sibte Abidi, 1994). It is not destined to be part of a more permanent corpus, and can be disposed of as soon as the translation is completed. Copyright permission is not required. Like "parallel texts", it can be either bilingual comparable or target monolingual. (Zanettin, 2002, p. 242)

Ad hoc corpora are virtual corpora compiled to perform a particular translation assignment in any directionality (translation into mother tongues, translation into non-mother tongues, or indirect translation). Their design involves quality rather than quantity: ad hoc corpora do not usually include many texts. Their texts are highly appropriate and comparable to the source text in terms of subject matter or genre. The main objective is to develop a quick, reliable, low cost resource that allows translators to meet the information needs arising from the translation assignment (conceptual, terminological, stylistic, discursive, etc.), find models during the re-expression stage, solve problems, make decisions and validate solutions. (Corpas-Pastor, 2004, p. 236) [Translated by the author of this paper] 
As seen in the above definition, one of the main differences between DIY corpora and stable corpora is that the former have to be compiled by the translator, who must thus have or acquire an in-depth knowledge of the source text, in addition to knowing how to locate parallel texts on the internet, download them and convert them for exploitation with corpus linguistics tools.

DIY corpora have been studied by several authors. Besides those involved in the CULT (Corpus Use and Learning to Translate) proceedings (Bernardini \& Zanettin, 2000; Zanettin, Bernardini \& Stewart, 2003; Beeby, Rodríguez-Inés \& Sánchez-Gijón, 2009), other authors have discussed how to compile and exploit corpora as translation aids. For example, Austermühl (2001), for whom "finding data on the worldwide web is no problem at all, but finding reliable information is a rather difficult task" (p. 52), proposes different ways to find parallel texts. Corpas-Pastor (2001, 2002, 2004), Sánchez-Gijón $(2004,2009)$ and Zanettin (2012) discuss how to compile DIY corpora, while Gallego-Hernández (2012, p. 151-182) proposes a theoretical and practical framework for doing so. The exploitation of corpora has turned out to be useful for translating in different domains, including medicine (Corpas-Pastor, 2001; Varela-Vila, 2009), law (Monzó-Nebot, 2008; Biel, 2010), business (Gallego-Hernández, 2012; Krüger, 2012), tourism (Corpas-Pastor \& Seghiri, 2009) and localisation (JiménezCrespo, 2009), amongst many others.

\section{The use of corpora in translation training}

As Beeby et al. (2009) state, there are two different yet complementary approaches to the use of corpora in translation training, namely corpus use for learning to translate and learning corpus use to translate. Basically, in the former approach, corpora are compiled by trainers and translator trainees merely exploit them as a translation aid. Trainers may also use corpora as a source of teaching materials. In the latter approach, the translator trainees themselves build and exploit corpora.

Different translator trainers from all over the world have been using corpora in their classrooms for different types of translation and language combinations, and demonstrating that translation quality improves when using these resources.

In the School of Applied Language and Intercultural Studies at Dublin City University (Ireland), Bowker (1998) conducted a study in which translator trainees used a specialised monolingual native-language corpus to carry out a specialised translation from a foreign language (French) into their native language (English). Her results showed that translation quality improved with respect to subject field understanding, terminology and idiomatic expressions.

Similarly, Zanettin (2001) describes a study with translator trainees from the School for Translators and Interpreters at the University of Bologna (Italy). In this case, a group of trainees used a specialised corpus consisting of texts about the Olympic Games to translate a short text from Italian into English. Among other things, the corpus allowed them "to contrast the source and target language at various levels, from single words and phrases to discourse functions" and facilitated the selection of equivalents. 
Varantola (2003) carried out a study in the Department of Translation Studies at the University of Tampere (Finland). She observed that a wide range of translation problems can be solved by the use of corpora, but pointed out that finding relevant information is difficult and compiling ad hoc corpora time-consuming. She also formulated different corpus-related competences, such as "corpus compilation" and "use of corpus information", which could be taught in translation training.

In the Universitat Autònoma de Barcelona (Spain), Rodríguez-Inés (2008, 2009, 2013) developed a theoretical framework for the use of corpus linguistics tools in translation training which includes the competence of "use of corpora to translate". She also designed a training course for using corpora, which is divided into seven units containing tasks involving translating general and specialised texts from English into Spanish and vice versa.

Monzó-Nebot (2008) proposed different corpus-driven activities in the context of legal translator training at Jaume I University (Spain). Among other things, these activities are for the purposes of raising translation trainees' awareness of universalising effects in legal discourse, introducing them to corpus linguistics tools and to legal phraseology, observing differences in structures and communicative situations, and acquiring terminology.

Cortez-Godínez (2010) describes his experience with a small group of translation trainees at the University of Baja California (Mexico). According to the feedback he received from them, he states that they were motivated by and welcomed the use of corpus linguistics tools.

At the University of Granada (Spain), López-Rodríguez \& Buendía-Castro (2011) introduced translator trainees to 'web for/as corpus' methodologies involving the use of the Sketch Engine software in the context of specialised translation. Among the findings of a survey the authors conducted which are of particular relevance to this study, $81 \%$ of translator trainees stated that they would use the Sketch Engine software again and would not want to have to continue translating using traditional methods.

In the context of an MA programme in specialised translation offered at Cologne University of Applied Sciences (Germany), Krüger (2012) implemented ad hoc 'web for/as corpus' methodologies with both the corpus use for learning to translate and learning corpus use to translate approaches. One of his exercises involved the translation of excerpts of an annual report from English into German. The survey that was subsequently conducted was positive and showed that DIY corpora were used in combination with the web as a corpus, in particular with WebCorp software. It also showed that the function for generating lists of frequent collocates was seen as particularly helpful.

In Denmark, Laursen \& Arinas-Pellón (2012) used corpora in translation classes and demonstrated the efficiency that comparable corpora offer when translating annual reports from Spanish into Danish, especially for the correction of draft translations and revision tasks. They state that "if this tool is used regularly in teaching translation, trainees will begin to find it useful on a daily basis as a supplement to dictionaries, the internet and parallel texts - and as a general reference point" (p. 66). 
In the context of business translation courses, Gallego-Hernández (2014) introduced translator trainees to ad hoc web for corpus methodologies and sent them a survey. The results showed two types of opinions about the difficulty of working with such methodologies. On one hand, there was a group of trainees who considered it neither easy nor difficult; on the other, a smaller group found it rather difficult. Additionally, the majority of trainees regarded the methodologies learned as useful for translation. In general, most of them found it interesting to build and exploit DIY corpora when dealing with business translation (especially when extracting terminology and conceptual parallelisms or chunks). However, there was a small group who did not seem to be willing to spend time on building personal linguistic resources.

\section{The use of corpora in professional translation}

We have seen above that both the corpus use for learning to translate and learning corpus use to translate approaches are being applied in translation training. Many translator trainees will probably work with corpora as professional translators in the future, but are such resources currently in use in professional translation?

Bowker (2004) states that "the uptake of corpora in the world of professional translators appears to have been considerably slower" (p. 13). She surveyed the Canadian market in order to find out to what extent professional translators make use of corpora. To do so, she analysed publications produced by associations and a database of job advertisements. Among her results, she found that even if professional translator associations were aware of the existence of corpora, their job advertisements never mentioned them, and professional translators themselves were more interested in translation memories.

A study carried out by Jääskeläinen \& Mauranen (2006) examined, among other things, the use of a corpus built by them and exploited by translators employed in the Finnish timber industry. The results showed that corpora were not as widely used as they had expected. The authors suggest stressing the need for corpus compilation guidelines and strategies, and for training for translators.

The MeLLANGE project (2006) conducted a survey involving 1015 respondents, mainly professional freelance translators from the UK with more than 5 years' experience. $58.2 \%$ of the responding translators did not use corpora in their work, most of them $(41 \%)$ because they had never heard of them. $20.2 \%$ used concordancers to exploit corpora and $82.4 \%$ were interested in learning more about their potential.

Few professional translators state that they do use corpora in their work. Wilkinson (2006) encourages professional translators to use corpora, although he recognises that building them is a "time-consuming process". In that regard, he advises against the use of corpora when "working on a one-off, relatively short special-field translation", but recommends it when faced with "a very large brief amounting to dozens or hundreds of pages", "working as an in-house translator for a company engaged in a specific sector" or "regularly translating texts belonging to one or several special fields". Maher, Waller \& Kerans (2008), according to whom "a corpus is not necessarily defined by the storage of texts in any particular form; any collection of model texts defined by appropriate criteria is a corpus", explain how they use not only concordancers but also desktop-based 
indexers to translate. They have even carried out various workshops about such methodologies.

Other researchers, such as Varela-Vila (2009, p. 814), claim that the use of corpora is a regular practice, because translators have already started to become aware of the potential of their exploitation. Pastor \& Alcina (2009) state that "in recent years, translators have increasingly turned to corpora as a resource in their terminology searches" (p. 13). However, Aston (2009) points out that corpus use "has not yet become widely established among professional translators" (p. IX-X). The low level of acceptance of corpora among such translators is said to be related to "anti-economic" reasons.

Scott (2012), who also carried out a survey based on the MeLLANGE questionnaire and found that $61 \%$ of professional translators did not use corpora in their work, presents an overview of "a project aimed at establishing whether the riches offered by corpora, long present in the world of academia, can at last be adopted by professional translators to their benefit, and, by extension, afford improvements to the quality of legal translations, rendering them closer to receivers' expectations and requirements". The results of her study are still to come, however.

\section{A study based on a survey of professional translators}

The previous short review of the literature about corpora and their relationship with the practice of translation has shown us that there seems to be no lack of work on the stages that the corresponding methodology involves or on the use of corpora in translation training. This could lead us to think that professional translators are indeed using corpora as translation resources. However, the exploitation of corpora is not without its problems. Stable corpora may not be suited to the needs of translators, not only because their content tends to be of a general nature but also because of usability issues (their interfaces are not usually suited to the practice of translation). On the other hand, ad hoc corpus methodologies involve different processes that require advanced technological or instrumental skills, especially when translators do not yet have their own corpora on their workstation. This raises the question of whether translators actually are using such methodologies. There seems, in fact, to be a great difference between the number of studies on how to use corpora and of those on the use of corpora in professional translation. The few existing studies of the latter kind have shown us that only a small minority of professional translators use corpora in their work; the majority do not seem to use this kind of resource at all. We believe that we are far from knowing whether professional translators are actually using corpora, exactly which translators are using them, what they think about them, etc. We feel, however, that the survey-based study presented below may contribute to answering some of those questions.

\section{Methodology}

The data set out below was collected by means of what Visauta-Vinacua (1989, p. 262264) calls a descriptive survey for specific purposes. Our aim, in what was a synchronic survey referring to facts and not feelings, was basically to try to describe what professional translators think about corpus methodologies applied to their work. The 
survey was hosted on the website of the University of Alicante. The questionnaire was available for respondents to complete from January to May 2013, and was sent to various translation agencies, discussion forums and more than 4500 certified translators in Spain.

The questionnaire consisted of three main types of question. The first type was related to the profile of the participating translators, establishing their nationality, age, main source of income (translation agencies, corporations unrelated to translation, translation for institutions, translation project managers, freelance translation and other sources of income) and years of experience. The second type dealt with their use of different translation resources. In particular, they were asked how often they use monolingual dictionaries, bilingual dictionaries, their own glossaries, term databases, glossaries on the internet, corpora, their own translation memories, shared translation memories, texts from the internet (Google) and machine translation systems. The five possible answers were never, almost never, sometimes, often and very often. The third type of question looked at different aspects of the use of corpora. Translators were asked about the kinds of corpora they use (commercial ready-made, free ready-made and DIY corpora on one hand; and general, specialised, monolingual and multilingual corpora on the other), what they use corpora for (text comprehension, term extraction, collocations and phraseology, general language, translation proof-reading, glossary creation and translation memory creation), and what kind of corpus software functions they find most useful (concordances, n-grams, wordlists, collocates and others). They were also asked about the kinds of translation assignment for which they usually build DIY corpora (an open question with no pre-established categories) and the stage of the translation assignment process (before, during or after the assignment) at which they do so. Finally, they were posed two questions concerning the usefulness of corpora (the four possible answers being useless, not very useful, useful and very useful) and whether they thought a specific training course in corpora for translators would help to improve their work (the two possible answers being yes and no).

\section{Informants}

The questionnaire was successfully completed by 581 translators of different nationalities, although in this study we only present the data from Spanish translators, that is to say 526 respondents of various ages (203 under 30 years old, 122 between 30 and 35 years old, 76 between 35 and 40 years old, 31 between 40 and 45 years old, and 95 over 45 years old) with different sources of income (25 working for translation agencies, 41 employed by other corporations unrelated to translation, 8 translating for institutions, 16 working as translation project managers, 291 working as freelance translators, and 145 with other sources of income) and varying amounts of experience (274 with less than 5 years of experience in translation, 112 with between 5 and 10 years, 69 with between 10 and 15 years, and 71 with over 15 years).

\section{Results}

Figure 1 shows the differences in the frequency of use of various translation resources. The most commonly used are bilingual dictionaries and Google, which more than $80 \%$ of respondents use often or very often. Machine translation and shared translation 
memories, meanwhile, are used "sometimes/often/very often" by $10 \%$ and $30 \%$ of them respectively.

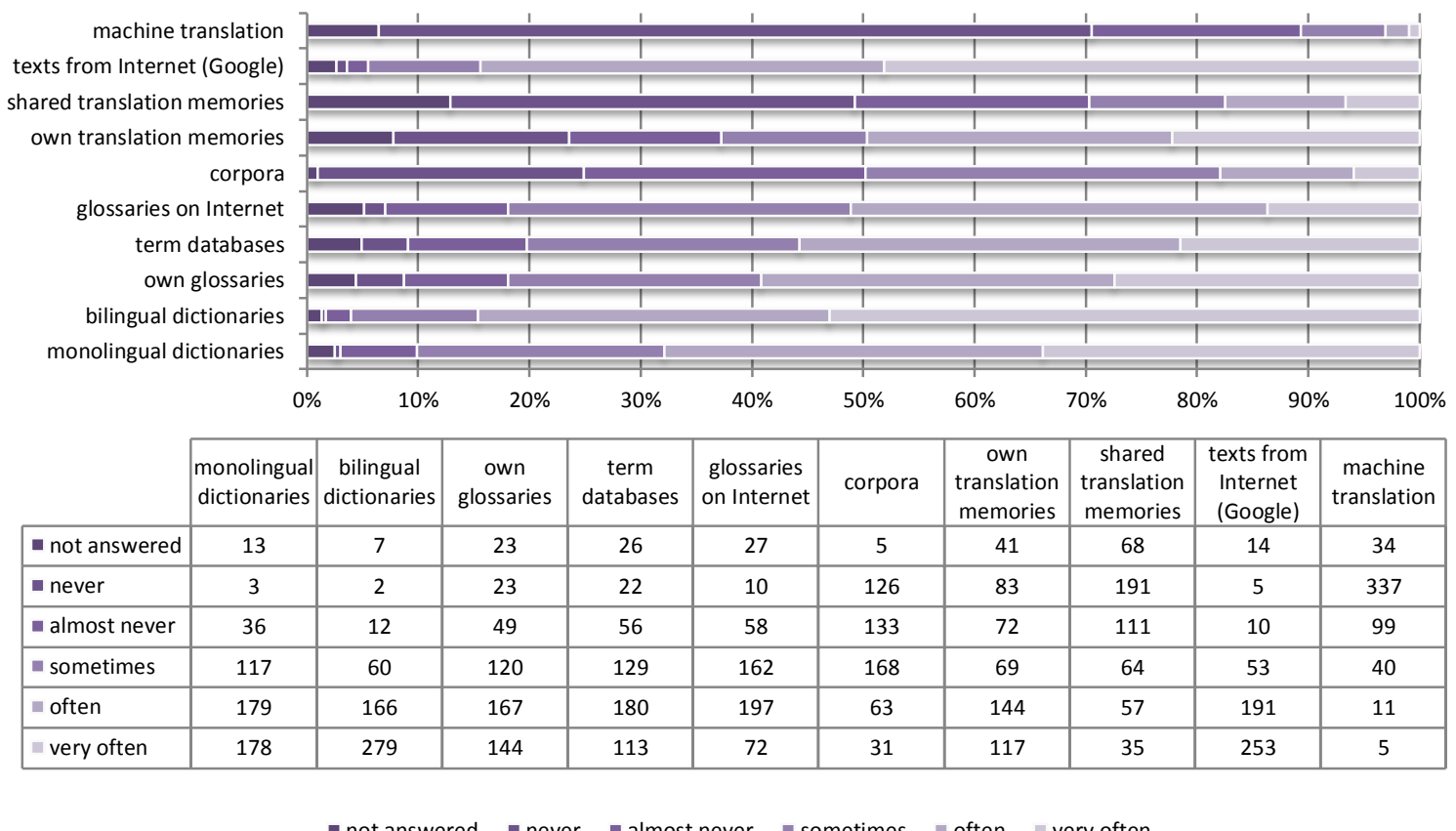

Figure 1: How often do you use these translation resources?

Figure 1 also shows how often translators use corpora. Nearly 50\% of respondents stated that they "never/almost never" use corpora to translate. Barely $30 \%$ answered "sometimes", and only $18 \%$ indicated that they use corpora "often/very often". If we break down these results on the basis of the respondents' main source of income, their age and their years of experience, there appears to be no significant difference in the proportions involved, as shown in Figures 2-4.

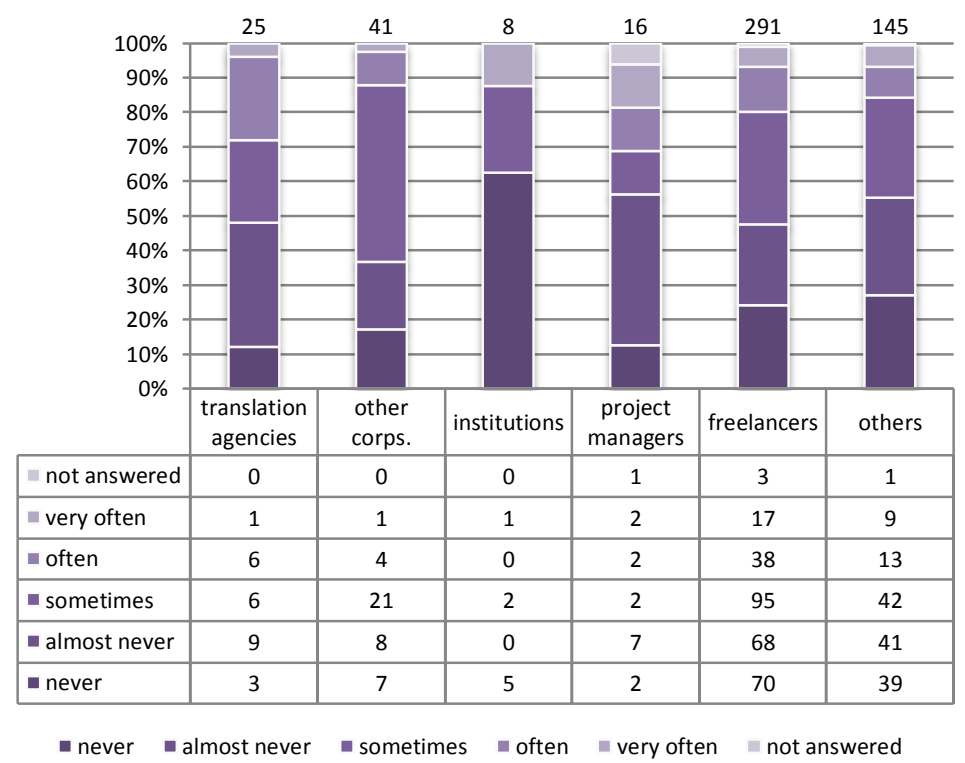

Figure 2: Frequency of use of corpora by main source of income 


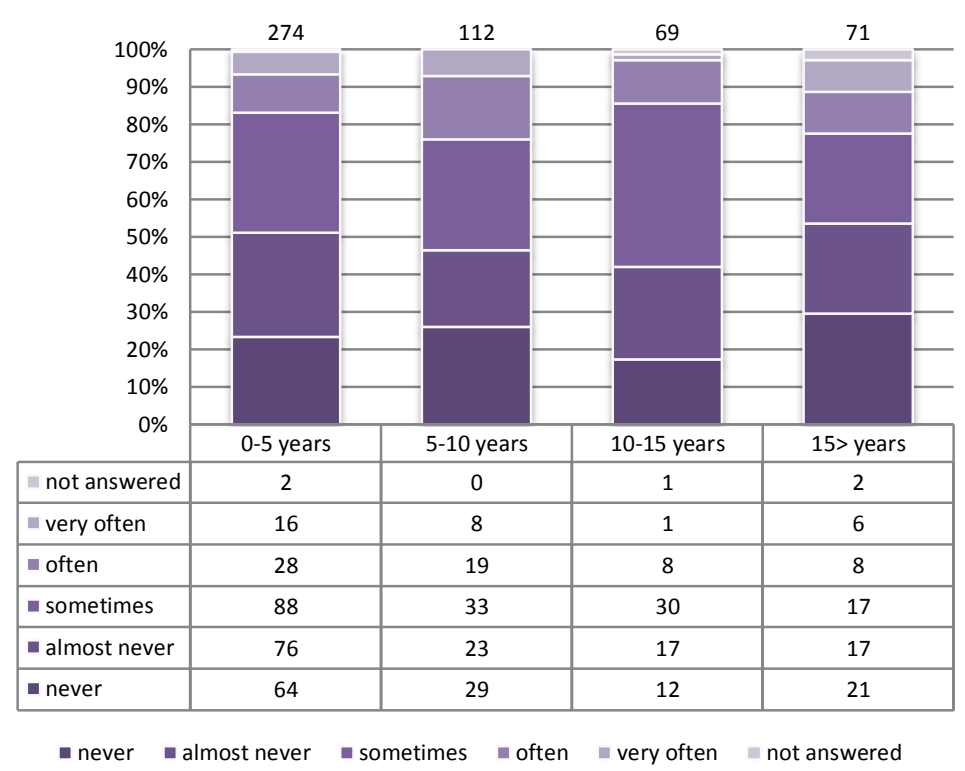

Figure 3: Frequency of use of corpora by years of experience

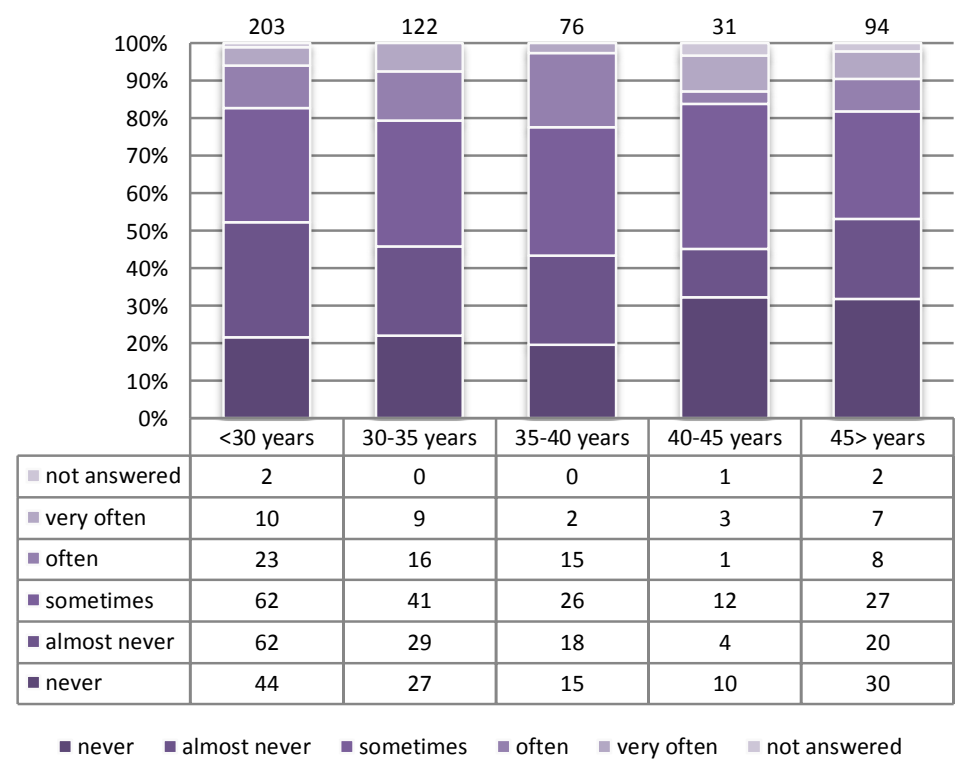

Figure 4: Frequency of use of corpora by age

Figures 5 and 6 show what types of corpora are used and what they are used for by the 262 translators who stated that they use corpora at least "sometimes" in their translation work. 


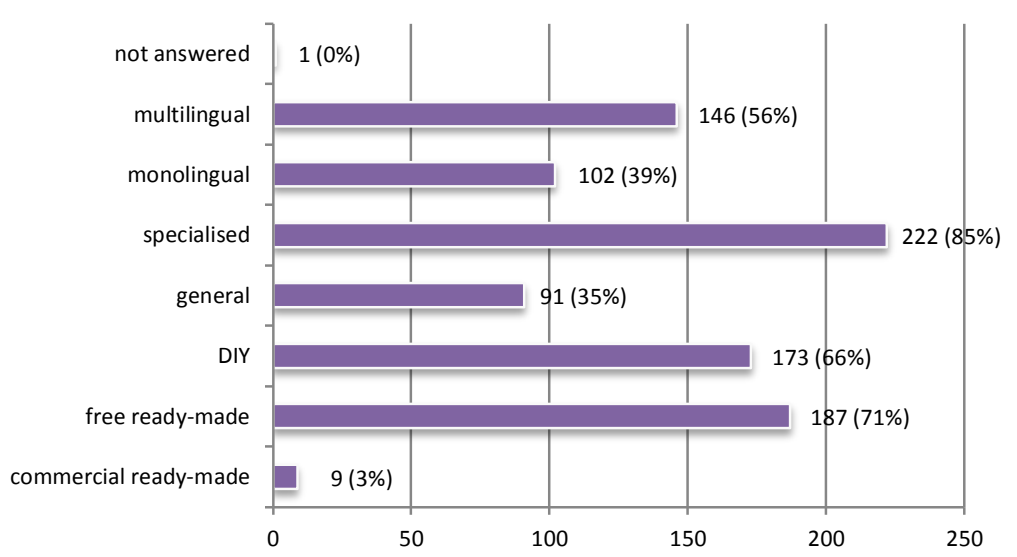

Figure 5: What kinds of corpora do you use?

The figure above reveals, on one hand, that translators prefer specialised (85\%) to general corpora $(35 \%)$, and multilingual $(56 \%)$ to monolingual corpora $(39 \%)$. On the other hand, the difference between using free online corpora (71\%) and compiling ad hoc corpora $(66 \%)$ is minimal. However, only $3 \%$ of translators stated that they pay to use corpora.

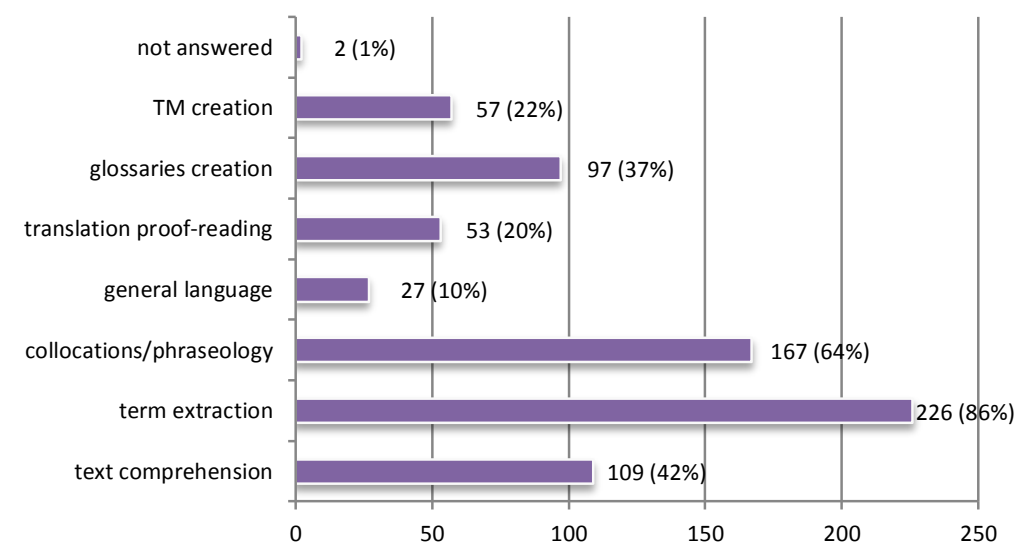

Figure 6: What do you use corpora for?

Term extraction stands out as the main purpose for which translators make use of corpora $(86 \%)$, followed by collocations and phraseology (64\%). Text comprehension is the third most frequent form of use (reported by $42 \%$ of translators), and glossary creation the fourth (37\% of respondents). Finally, just $10 \%$ of translators stated that they use corpora to look for information about general language. 


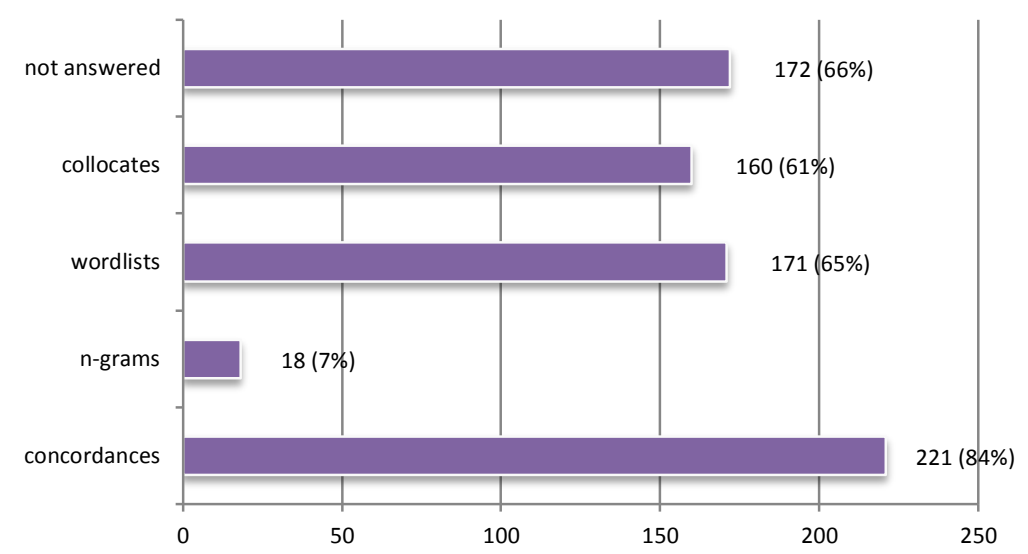

Figure 7: What kind of functions of corpus software do you think are most useful for translators?

Figure 7 concerns the use of different functions offered by corpus software. Concordances are the most frequently used of such functions, followed by searches for collocations and wordlists. The use of n-grams appears to be much less common than that of the other functions. This may be due to various reasons, specifically that the ngrams function has other names in certain software; not all software actually has this function; it may be related to collocations in certain software; or respondents may not be familiar with the term n-grams (only one respondent recognised it).

Translators were also asked whether there was another application or function normally absent from corpus software which they would like to see included. Most of them did not answer or simply answered "no". A few respondents said that they regret the lack of automatic tagging or truncation options.

Translators also specified the kind of translation assignments for which they usually build DIY corpora. 110 informants answered the corresponding open question. Most of them stated that they normally compile corpora for specialised translation (legal, technical, business, academic, scientific, medical). Others affirmed that they do so when facing large translation assignments and when translating texts related to unfamiliar fields.

They also specified at which stage of the translation assignment process they compile their corpora. Most of them (56\%) build corpora during the translation assignment, but a fairly large number of them also do so before (23\%) and after (35\%) the assignment (maybe for editing/revision/checking/proofreading purposes or because they have recognised the need to compile a corpus for future assignments), as shown in Figure 8. 


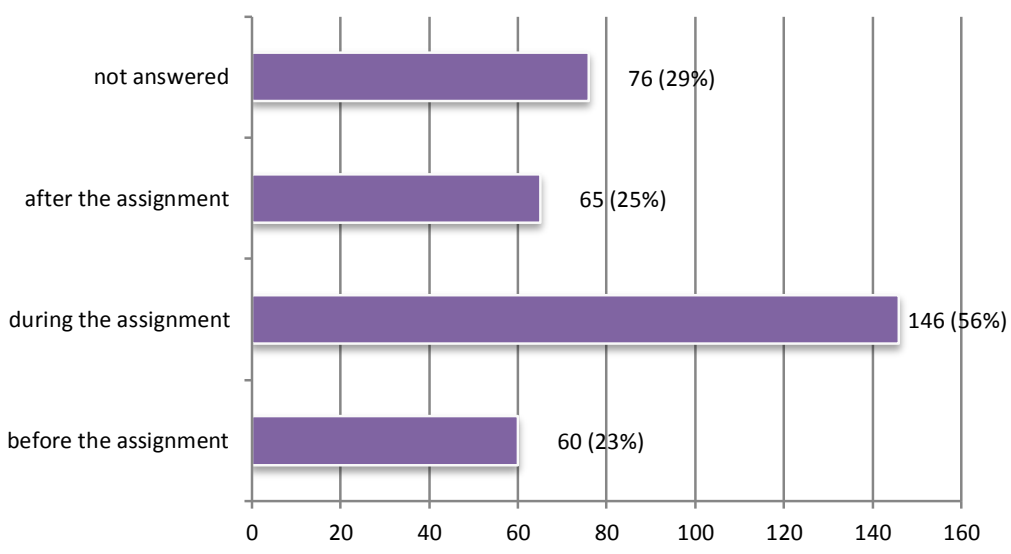

Figure 8: At which stage of the translation assignment process do you build DIY corpora?

The penultimate question focused on the usefulness of corpora (see Figure 9). The majority of the translators who use corpora "sometimes/often/very often" (we have called them users) stated that corpora are useful (66\%) or very useful (28\%) for translating. Very few respondents (12) answered that corpora are of little use. Surprisingly, while $42 \%$ of the respondents who stated that they "never" or "almost never" use corpora (we have called them non-users) did not answer this question, 36\% stated that corpora are useful, and only $20 \%$ said that they are useless or not very useful.

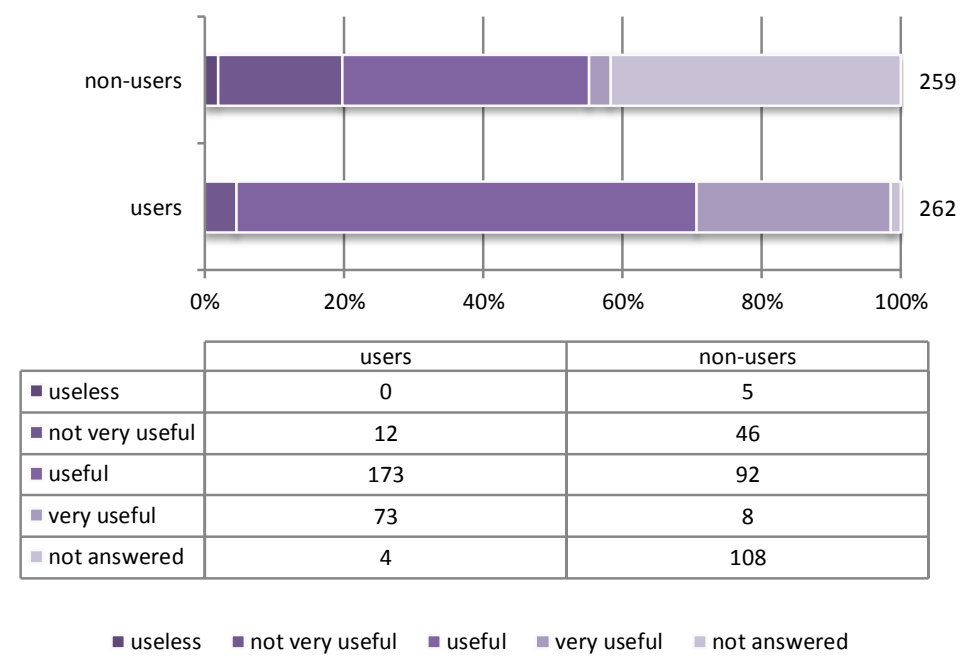

Figure 9: How useful are corpora for your work?

The final question (see Figure 10) concerned specific training courses in corpora for translators. Corpus users seem to believe that they could improve their work by attending such courses, an idea shared by $50 \%$ of non-users. Only $7 \%$ of users and $12 \%$ of non-users thought otherwise. $31 \%$ of non-users did not answer this question. 


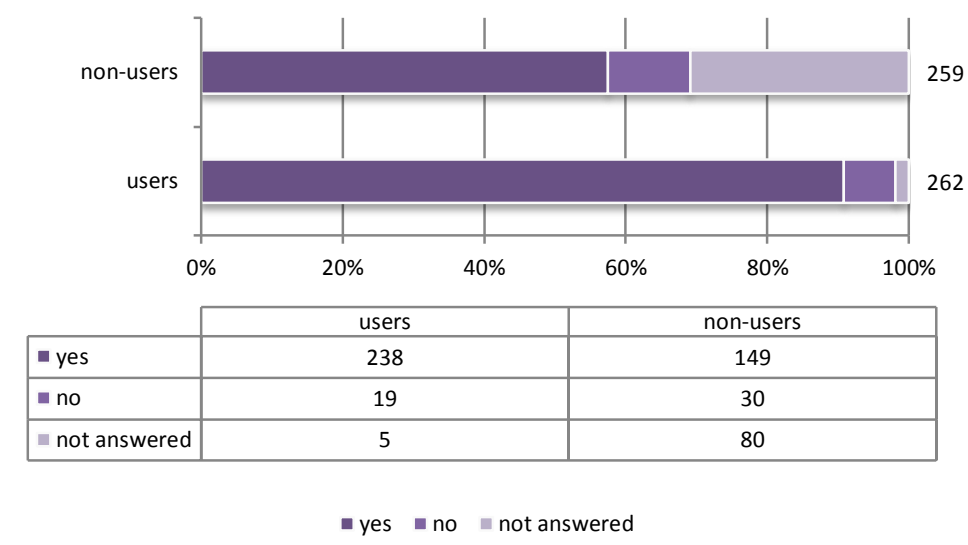

Figure 10: Do you think a specific training course in corpora for translators would help to improve your work?

\section{Conclusions}

In this paper, we have tried to describe the relationship between Spanish translators and the use of corpora in translation practice. The overall results of our survey suggest that the inclusion of skills related to the use of corpora in the design of translation courses, as well as the increasingly abundant literature on building and exploiting corpora in translation practice, are beginning to bear fruit, as almost $50 \%$ of respondents stated that they use corpora "sometimes/often/very often" in their work. This can be explained in various ways. Translators may ignore such resources; they may use them in combination with other resources; they may not use them for every translation assignment; they may lack adequate skills; or they may think that corpora are useless for translating.

It also seems to be clear, based on our results, that the concepts of corpora as a translation resource and their exploitation may remain poorly defined among professional translators, or at least have rather diffuse boundaries, a factor that hinders the design of survey questionnaires involving these professionals and may cause respondents not to completely understand certain questions. For example, all the documents saved in a translator's workstation may not only be considered a corpus but can also be exploited with different applications, such as desktop search tools, which may not be strictly considered conventional corpus linguistics tools. Corpus linguists would not really view the above as corpora or corpus tools, but it seems that some professional translators consider such collections of texts to be corpora or archives, and exploit them with the aid of 'information retrieval' tools.

The translators who do use corpora make greater use of specialised and multilingual corpora than of general and monolingual corpora, and prefer stable corpora, although many of them are also accustomed to compiling their own corpora for exploitation with corpus linguistics tools. Few translators pay to use commercial, ready-made, stable corpora. The majority of translators use corpora in relation to terminology and phraseology, and employ different functions of corpus linguistics tools, such as wordlists, concordances and collocations. These translators normally use corpora for 
specialised translation assignments (legal, technical or economic), as well as for work in unfamiliar fields and large assignments. Overall, they consider corpora useful or very useful, and most of them believe that specific training would help them to optimise their work.

As the non-Spanish translators were eliminated from our analysis in order to study the Spanish context and give this paper cohesion, the question of whether the data for such translators differs significantly from that of their Spanish counterparts may arise. A quick scan of the data in its entirety reveals that the results do not differ significantly from those presented in this paper. Nevertheless, a more detailed analysis, based not only on a larger number of respondents but also on specific countries or languages, should be carried out in order to provide internationally valid results.

Finally, as it appears that translator trainees in Spain are receiving training in corpus linguistics tools little by little, and that very few courses on corpus use are available for professional translators, it seems appropriate to continue to raise awareness about corpus resources not only among translator trainees but also translator trainers, who are the real transmitters of this type of methodology, and professional translators who do not as yet use corpora, since they do not seem entirely sceptical about these resources.

\section{Acknowledgements}

This paper is part of the research project "GRE11-11 COMENEGO (Corpus Multilingüe de Economía y Negocios): adecuación de recursos textuales para la práctica de la traducción de textos especializados / Multilingual Corpus of Business and Economics: adaptation of textual resources to the practice of specialised translation", supported by the Office of the Vice President for Research, Development and Innovation of the University of Alicante.

\section{References}

Ahmad, K., Holmes-Higgin, P., \& Sibte Abidi, R. (1994). A description of texts in a corpus: 'Virtual' and 'real' corpora. In W. Martin, W. Mejis, M. Moerland, E. Ten Pas, P. Van Sterkenburg \& P. Vossen (Eds.), EURALEX 190 proceedings (pp. 390-402). Amsterdam: Vrije Universiteit.

Aston, G. (1999). Corpus use and learning to translate. Textus, 12, 289-314. Retrieved from http://www.sslmit.unibo.it/ guy/textus.htm

Aston, G. (2009). Foreword. In A. Beeby, P. Rodríguez-Inés \& P. Sánchez-Gijón (Eds.), Corpus use and translating (pp. IX-X). Amsterdam \& Philadelphia, PA: John Benjamins.

Austermühl, F. (2001). Electronic tools for translators. Manchester \& Northampton, MA: St. Jerome.

Baker, M. (1995). Corpora in translation studies: An overview and suggestions for future research. Target, 72, 223-244.

Beeby, A., Rodríguez-Inés, P., \& Sánchez-Gijón, P. (Eds.). (2009). Corpus use and translating. Amsterdam \& Philadelphia, PA: John Benjamins.

Bernardini, S., \& Zanettin, F. (Eds.). (2000). I corpora nella didattica della traduzione: Corpus use and learning to translate. Bologna: CLUEB. 
Biel, Ł. (2010). Corpus-based studies of legal language for translation purposes: Methodological and practical potential. In C. Heine \& J. Engberg (Eds.), Reconceptualizing LSP. Online proceedings of the XVII European LSP symposium 2009. Aarhus: Aarhus School of Business. Retrieved from http://bcom.au.dk/fileadmin/www.asb.dk/isek/biel.pdf

Bowker, L., \& Pearson, J. (2002). Working with specialized language: A practical guide to using corpora. London: Routledge.

Bowker, L. (1998). Using specialized monolingual native-language corpora as a translation resource: A pilot study. Meta, 43(4), 631-651.

Bowker, L. (2004). Corpus resources for translators: academic luxury or professional necessity?. TradTerm, 10, 213-247.

Corpas-Pastor, G., \& Seghiri, M. (2009). Virtual corpora as documentation resources: Translating travel insurance documents English-Spanish. In A. Beeby, P. Rodríguez-Inés \& P. Sánchez-Gijón (Eds.), Corpus use and translating (pp. 75107). Amsterdam \& Philadelphia, PA: John Benjamins.

Corpas-Pastor, G. (2001). Compilación de un corpus ad hoc para la enseñanza de la traducción inversa especializada. Trans, 5, 155-184.

Corpas-Pastor, G. (2002). Traducir con corpus: de la teoría a la práctica. In J. GarcíaPalacios \& M. ${ }^{\mathrm{a}}$ T. Fuentes-Morán (Eds.), Texto, terminología y traducción [Text, terminology and translation] (pp. 189-226). Salamanca: Almar.

Corpas-Pastor, G. (2004). Localización de recursos y compilación de corpus vía internet: Aplicaciones para la didáctica de la traducción médica especializada. In C. Gonzalo-García \& V. García-Yebra (Eds.), Manual de documentación y terminología para la traducción especializada [A handbook of documentation and terminology for specialized translation] (pp. 223-258). Madrid: Arco.

Cortez-Godínez, J. (2010). El corpus ad hoc como herramienta de traducción. In D. Heffington \& A. Marín-Marín (Eds.), Memorias del VI foro de estudios en lenguas internacional [Proceedings of the 6th international congress on languages] (pp. 73-95). Chetumal: Universidad de Quintana Roo. Retrieved from http://fel.uqroo.mx/adminfile/files/memorias/cortez_godinez_jose.pdf

Gallego-Hernández, D., \& Krishnamurthy, R. (2013). COMENEGO (Corpus Multilingüe de Economía y Negocios): design, creation and applications. Empirical language research, 7. Retrieved from http://ejournals.org.uk/ELR/article/2013/1

Gallego-Hernández, D. (2012). Traducción económica y corpus: del concepto a la concordancia [Business translation and corpus: From concept to concordance. Applied to French and Spanish]. Alicante: Servicio de publicaciones de la Universidad de Alicante.

Gallego-Hernández, D. (2014). Business translation training and DIY corpora. In P. Sánchez-Gijón, B. Mesa-Lao \& O. Torres-Hostench (Eds.), The coming of age of translation technologies in translation studies (pp. 115-139). Oxford, Bern, Berlin, Bruxelles, Frankfurt am Main, New York, NY \& Wien: Peter Lang.

Jääskeläinen, R., \& Mauranen, A. (2006). Translators at work: a case study of electronic tools used by translators in industry. In G. Barnbrook, D. Pernilla \& M. Mahlberg (Eds.), Meaningful texts. The extraction of semantic information from monolingual and multilingual corpora (pp. 48-53). London \& New York, NY: Continuum. 
Jiménez-Crespo, M. A. (2009). El uso de corpus textuales en localización. Tradumàtica, 7. Retrieved from http://www.raco.cat/index.php/Tradumatica/article/viewFile/154832/206726

Krüger, R. (2012). Working with corpora in the translation classroom. Studies in second language learning and teaching, 4, 505-525.

Laursen, A., \& Arinas-Pellón, I (2012). Text corpora in translation training. A case study of the use of comparable corpora in classroom teaching. The interpreter and translator trainer, 61, 45-70.

López-Rodríguez, C., \& Buendía-Castro, M. (2011). En busca de corpus online a la carta en el aula de traducción científica y técnica. Trans-kom, 41, 1-22.

Maher, A., Waller, S., \& Kerans, M. (2008). Acquiring or enhancing a translation specialism: the monolingual corpus-guided approach. Jostrans, 10. Retrieved from http://www.jostrans.org/issue10/art_maher.php

MeLLANGE (2006). Corpora \& e-learning questionnaire. Results summary. Retrieved from http://mellange.eila.jussieu.fr/Mellange-Results-1.pdf

Monzó-Nebot, E. (2008). Corpus-based activities in legal translator training. The interpreter and translator trainer, 22, 221-252.

Pastor, V., \& Alcina, A. (2009). Search techniques in corpora for the training of translators. In I. Ilisiei, V. Pekar \& S. Bernardini (Eds.), Proceedings of the international workshop on natural language processing methods and corpora in translation. Lexicography, and language learning (pp. 13-20). Borovets: Incoma. Retrieved from http://aclweb.org/anthology//W/W09/W09-42.pdf

Rodríguez-Inés, P. (2008). Uso de corpus electrónicos en la formación de traductores inglés-español-inglés ( $\mathrm{PhD}$ Thesis). Universitat Autònoma de Barcelona, Barcelona.

Rodríguez-Inés, P. (2009). Evaluating the process and not just the product when using corpora in translator education. In A. Beeby, P. Rodríguez-Inés \& P. SánchezGijón (Eds.), Corpus use and translating (pp. 129-149). Amsterdam \& Philadelphia, PA: John Benjamins.

Rodríguez-Inés, P. (2013). Electronic target-language specialised corpora in translator education: building and searching strategies. Babel, 59(1), 57-77.

Sánchez-Gijón, P. (2002). Aplicaciones de la lingüística de corpus a la práctica de la traducción. Complemento de la traducción asistida por ordenador. Terminologie et Traduction, 2, 84-106.

Sánchez-Gijón, P. (2004). L'ús de corpus en la traducció especialitzada: compilació de corpus ad hoc i extracció de recursos terminològics [The use of corpora in specialized translation: compilation of ad hoc corpora and extraction of terminological resources]. Barcelona: Universitat Pompeu Fabra.

Sánchez-Gijón, P. (2009). Developing documentation skills to build do-it-yourself corpora in the specialised translation course. In A. Beeby, P. Rodríguez-Inés \& P. Sánchez-Gijón (Eds.), Corpus use and translating (pp. 109-127). Amsterdam \& Philadelphia, PA: John Benjamins.

Scott, J. (2012). Towards professional uptake of DIY electronic corpora in legal genres. In M. Sánchez (Ed.), Salford working papers in translation and interpreting (Vol. 1). Salford: University of Salford. Retrieved from http://www.salford.ac.uk/_data/assets/pdf_file/0010/229492/WorkingPapersTand-I.Scott.pdf 
Varantola, K. (2000). Translators, dictionaries and text corpora. In S. Bernardini \& F. Zanettin (Eds.), I corpora nella didattica della traduzione: Corpus use and learning to translate (pp. 117-133). Bologna: CLUEB.

Varantola, K. (2003). Translators and disposable corpora. In F. Zanettin, S. Bernardini \& D. Stewart (Eds.), Corpora in translator education (pp. 55-70). Manchester $\&$ Northampton, MA: St. Jerome.

Varela-Vila, T. (2009). Córpora ad hoc en la práctica traductora especializada: aplicación al ámbito de las enfermedades neuromusculares. In P. Cantos-Gómez \& A. Sánchez-Pérez (Eds.), A survey on corpus-based research. Panorama de investigaciones basadas en corpus (pp. 814-831). Murcia: Asociación española de lingüística del corpus.

Visauta-Vinacua, B. (1989). Técnicas de investigación social. I Recogida de datos [Social research techniques. I Data collection]. Barcelona: PPU.

Wilkinson, M. (2006). Compiling corpora for use as translation resources. Translation journal, 101. Retrieved from http://www.translationdirectory.com/article910.htm

Zanettin, F. (2001). Swimming in words: Corpora, translation, and language learning. In G. Aston (Ed.), Learning with corpora (pp. 177-197). Houston, TX: Athelstan.

Zanettin, F. (2002). DIY corpora: the WWW and the translator. In B. Maia, J. Haller \& M. Ulrych (Eds.), Training the language services provider for the new millennium (pp. 239-248). Porto: Universidade do Porto.

Zanettin, F. (2012). Translation-driven corpora. Manchester \& Kinderhook, NY: St. Jerome.

Zanettin, F., Bernardini, S., \& Stewart, D. (Eds.). (2003). Corpora in translator education. Manchester \& Northampton, MA: St. Jerome. 